DOI: https://doi.org/10.24297/jssr.v17i.8970

\title{
The Benefits of Project-based Language Learning: A Case Study in a Malaysian Secondary School
}

\author{
${ }^{1}$ Ramesh Sathappan, ${ }^{2}$ Premaraj Gurusamy \\ 1Department of Languages, Temenggong Ibrahim Teacher Education Institute, Malaysia, \\ ${ }^{2}$ Kolej Matrikulasi Kejuruteraan Johor/UTM, Malaysia \\ jhnmesh@yahoo.com, premrajg755@gmail.com
}

\begin{abstract}
Project -based learning (PBL) is a student-centered teaching approach that organizes learning around projects. It increases students' motivation to learn and prepares them for the $21^{\text {st }}$ century classroom demands through developing real-world experience. The purpose of this study is to explore the benefits of project-based learning on students' in a Malaysian secondary school. This is a qualitative case study. The sample consists of 3 teachers' from a secondary school in Malaysia. Semi-structured interviews were conducted with the participants. The collected data were coded and analyzed using thematic analysis. The study revealed that the participants perceived PBL as a beneficial teaching approach that has the potential to increase student-teachers' engagement and help them understand more deeply the subject content through self-learning and learning by doing. The advantages of using PBL discussed by the participants were improved lecturer-student and student-lecturer relationships, skill development and real-world practice. The results of this research show that student-teachers' understand PBL from both positive and negative perspectives. It is considered that findings of this study would improve students-teachers' motivation and equip them with the necessary skills to successfully implement PBL.
\end{abstract}

Keyword: Project-based learning, benefits, teachers,

\subsection{INTRODUCTION}

Project-based learning (PBL) is a model that organizes learning around projects. . Projects are complex tasks, based on challenging questions or problems that involve students in design, problem-solving, decision making or investigative activities; give students the opportunity to work relatively autonomously over extended periods of time; and culminate in realistic products or presentations (Jones, Rasmussen, \& Moffitt, 1997; Thomas (2000). Students work on a project over an extended period of time that engages them in solving a real-world problem or answering a complex question. They demonstrate their knowledge and skills by developing a public product or presentation for a real audience. As a result, students develop deep content knowledge as well as critical thinking, creativity, and communication skills in the context of doing an authentic, meaningful project. Project Based Learning (PBL) unleashes a contagious, creative energy among students and teachers. Project-based Learning ( $\mathrm{PBL}$ ) has increasingly been trialled and adopted across a diversity of educational institutions worldwide (Lehmann et al., 2008; Kolmos, 2009).

The need for critical thinking has been identified as an important driver for PBL. The approach has been argued to highlight the process and power structures behind knowledge creation, engendering critical thinking and helping students consider alternative ways of thinking and acting (Von Kotze and Cooper, 2000). Furthermore, students' enjoyment of PBL activities are linked to motivation to learn. Motivation is the ability of PBL to provide the type of skills, behaviors and understanding needed to tackle challenges in an environment of increasing complexity, where problems and projects transcend well-defined disciplines and sectors. The element of student choice enabled by project-based learning is argued to underpin increased levels of motivation (Blumenfeld et al., 1991; Kahn and O'Rourke, 2004).

PBL is described as a learning cycle in which students initially encounter a problem; reasoning skills are then developed and learning needs identified with the teacher support. This is followed by individual study and a cooperative phase in which the knowledge is applied to the problem (Perrenet et al., 2002). Here students identify and seek the information needed rather than drawing on the existing knowledge with which to explore 
the problem. Adoption of PBL in Higher Education also takes place in response to a perceived need for graduates to be equipped with skills relevant to future employers (Kolmos, 2009). These calls derive from government, industry and professional accreditation bodies as well as students facing highly competitive job markets (Lehmann et al., 2008).

\subsection{PROBLEM STATEMENT}

With the accelerating pace of the current world, educators are expected to adapt and rise to changes and new challenges in education. The $21^{\text {st }}$ century requires educators to use new ways of learning and teaching that will provide students more freedom in the expression of ideas. Malaysia sought to replace traditional academic strategies of memorization and passive learning by more student-centered learning. However, this kind of shift requires a new type of approach that is geared toward student-centered learning. PBL has emerged as one of the most prominent approaches for responding to these needs and demands and has gained mush attention of the Malaysian educators.

Krajcik and Blumenfeld (2006) state that almost all students are bored in class. Studies reveal that instructional methods such as group projects, projects and lessons involving technology and presentations are among the instructional methods most favoured by students, while uninteresting and irrelevant learning materials and the absence of interaction with teachers are demotivating factors (Yazzie-Mintz, 2010). PBL organizes learning around projects, provides students with an opportunity to create final artifacts using technology and present their work to the real audience (Thomas, 2000). It gives them excitement of learning and raising their interest in solving real-world problem (Bell,2010). Moreover, learners get to enjoy the learning process, as it includes the focus of their interests and allows them to learn by applying a hands-on approach. The important point is that students will have a chance to deeper understand the subject content through gaining real-life experience (Harringan, 2014).

In recent years, PBL has been integrated into instructional practices of many schools in Malaysia. PBL is presented as an effective student-centered learning method with the variety of benefits for students despite imposing some difficulties for learners. Many studies on teacher perceptions about PBL (Baysura, Altun \& Toy, 2016, Van den Bergh, 2006) seem to attest to that. However, to date, such views on PBL have been based mostly on international experience, and there is a shortage of research reflecting the Malaysian context. It remains unclear how Malaysian educators understand PBL. Therefore, this study seeks to investigate the benefits about the project-based learning in Malaysia.

\subsection{SIGNIFICANCE OF THE STUDY}

The results of this study could be beneficial for teachers, as it would help them reflect on their own practice in using PBL. The benefits from PBL could provide insights in overcoming the challenges that both teachers and students face. It will be helpful as their voices would be heard by the school administration, which would have the opportunity to think of the most effective methods and ways of overcoming the challenges in using PBL.

\subsection{OBJECTIVE OF THE STUDY}

The objective of this qualitative study is to find out the benefits of project-based learning (PBL) in a Malaysian Secondary school.

\subsection{LITERATURE REVIEW}

According to Fallik, Eylon, and Rosenfeld (2003), teachers identified more benefits of using PBL than difficulties. Benefits were mentioned mainly for students compared to teachers. They are enhanced collaboration with colleagues to deal with PBL issues (Harrigan, 2014; Tamim \& Grant, 2013) and better relationships between students and teachers (Hugerat, 2006; Thomas, 2000; Va den Bergh, et al., 2006). Other benefits are reported for students, such as increased engagement, skills development, improve academic achievement, and other benefits.

The first major benefit of using PBL is the increased engagement and motivation to learn (Bas, 2011; Bell, 2010; Hugerat, 2016; Larmer et al., 2015). Harringan (2014), krajcikn and Blumenfeld (2006), and Kubiatko and Vaculova (2011) believe that PBL raises students' engagement in various investigations where students can deal 
with real issues and learn experiences beyond the classroom. According to Thomas (2000, p.3), these investigations may be "design, decision-making, problem-finding, problem-solving, discovery or model-building processes". Students are motivated in learning because PBL provides them with hands-on approach to content (Holm, 2011). There is a slightly different perspective from Worthy (2000), who suggests that students using PBL are motivated and enjoyed because they have that autonomy they miss in the traditional approach (Yam \& Rossini, 2010). Yan \& Rossini (2010) believe that teachers are key figures in motivating students and creating the collaborative atmosphere in the classroom.

Students involved in PBL activities have a chance to develop a wide variety of skills (bell, 2010, Harmer \& Stokes, 2014; Hugerat, 2016). Researchers claim that PBL enhances $21^{\text {st }}$ century skills (Bell, 2010; Harmer \& Stokes, 2014). Furthermore, Ravitz and Blazevski (2010) found that effective use of PBL by teachers who received extended professional development on PBL can lead to the development of $21^{\text {st }}$ century skills by students and have an enormous impact on $1^{\text {st }}$ century teaching and leaning. In addition to $21^{\text {st }}$ century skills, Larmer et at. (2015) also on "success skills", such as interdisciplinary skills, soft skills, teamwork skills and time-management skills. They suggest that all these skills might be necessary for their future carriers. As a group work approach, PBL also provides learners with opportunities to gain collaboration and communication skills (Bas, 2011; Bell, 2011; Krajcik \& Blumenfeld, 2006). In addition to the mentioned skills, PBL also develops laboratory skills, information retrieval skills, interpersonal abilities (Frank et al., 2003), research skills, communication skills, and time-management skills (Tamim \& Grant, 2013).

Researchers provide evidence regarding the impact of PBL on the growth of academic achievement. Holm (2011) provides a view of research studies conducted regarding the effectiveness of PBL in preschool, elementary and secondary school settings. All studies indicate positive attitude of students towards PBL and demonstrate the growth in academic achievement after using PBL. DiEnno and Hilton (2005) state that students engaged in PBL show significantly high knowledge results because PBL provided them with the opportunity to learn by doing (Baumgartner \& Zabin, 2008). Moreover Harringan (2014) examined teachers' experiences of integrating PBL into the classroom. The participants were experienced teachers of primary schools who mentioned the academic success as the main benefit of implementing PBL in all classes. Participants of this study reported that their students to work harder and better understood the topic during PBL activities.

One of the advantages of using PBL is the improved relationship between students. PBL promotes support, understanding, and respect among students, creating a pleasant collaborative atmosphere in the classroom (Baumgartner \& Zabin, 2008). According to Bell (2010), students working in groups also motivate and help each other because they have a common goal and in order to finish and get a successful final product, every member of the group must contribute equally. Students learn how to organize work, communicate and deal with conflicts in groups. However, Hugerat (2016) did not find any significant differences between PBL and non-PBL students in terms of student-student relationships. On the other hand, many scholars agree that PBL improves relationships between students and teachers (Hugerat, 2016; Nicola \& Allison, 2014; Thomas, 2000; Van de Bergh et al., 2006).

Another vital advantage of implementing PBL is the real-world practice (Bell, 2010; Van den Bergh et al., 2006; Yam \& Rossini, 2010). Students involved in PBL engage in real world activities, meaningful problems which are interesting and important to them and are similar to what adult professionals do (Krajcik \& Blumenfed, 2006; Larmer et al., 2015).

\subsection{RESEARCH DESIGN}

This research study was carried out to investigate the benefits of PBL from three teachers in a Malaysian Secondary School. The nature of the research problem determines whether the research should be qualitative or quantitative (Creswell, 2012). According to Merriam (2009), qualitative researchers are interested in understanding how people interpret their experiences, how they construct their words, and what meaning they attribute to their experiences. Thus a qualitative approach was appropriate for this study to fully explain the experiences of the participants and gather the necessary data to answer the research question.

The research design for this study was a qualitative case study to explore the teachers perceptions of the benefits of PBL in a Malaysia Secondary School. A case study was used to document the experiences of 
teachers within a natural setting. It is also used to collect data from multiple sources and perspectives. Therefore, this study utilized a case study research design using interviews. Through a case study approach, this study involved participants' experiences, perceptions, and feelings gathered through rich, thick descriptions obtained by interviews (Creswell, 2012; Lodico et al., 2010). According to Creswell (2009), qualitative researchers collect data by examining documents, observing behaviour, or interviewing participants. In this study, qualitative methods were utilized to facilitate an understanding of how teachers perceptions of the benefits of using PBL.

Qualitative research involves an interpretive, holistic approach to what is being studied (Creswell, 2009). Because it best explores the question of what and how, qualitative research was chosen as the methodology for this study. In this study, the qualitative method facilitated an understanding of how the 3 teachers perceived and interpret their experiences. Instead of studying large groups, qualitative researchers conduct a more in-depth study on a limited number of participants (Creswell, 2012; Lodico at al., 2010). Because this research focus is on a Secondary School, a case study design offers the best research design because it involves the depth examination of a single case (Creswell, 2012). This case study provided a systematic method for collecting and analyzing data, as well as reporting results. An intrinsic case study is used when a reearcher is interested in a particular individual, group, event, or organization (Hancock \& Alogozzine, 2011; Merriam, 2009).

The data collection procedure used to address the research question for this qualitative study was a oral interview with the teachers. According to Creswell (2009) and Merriam (2009), data collection in the forms of interviews is considered a common approach in educational research. The data were collected by interacting with the selected participants. The type of data collected was open-ended interviews. The open-ended interviews allowed first-hand accounts of participants' thoughts, ideas, and experiences.

\subsection{RESEARCH METHODOLOGY}

Research methods used in this study are interviews. The interviews are semi-structured and are used to generate data from secondary school teachers. A total of three teachers are interviewed for this research. The teachers are currently teaching English. Mathematics and Physics in the particular school. The issues of suitability and reliability as well as the process of sampling, administration and analysis of the instrument of data collection is discussed in the following section.

\subsubsection{Interview}

Interviews are a systematic way of talking and listening to people and are another way to collect data from individuals through conversations. The researcher or the interviewer often uses open questions. Data is collected from the interviewee. The researcher needs to remember the interviewer's views about the topic is not of importance. The interviewee or respondent is the primary data for the study. Interviewing is a way to collect data as well as to gain knowledge from individuals. Kvale (1996) regarded interviews as "... an interchange of views between two or more people on a topic of mutual interest, sees the centrality of human interaction for knowledge production, and emphasizes the social situatedness of research data."

Interviews are ways for participants to get involved and talk about their views. In addition, the interviewees are able to discuss their perception and interpretation in regards to a given situation. It is their expression from their point of view. Cohen, Manion and Morrison (2000) explain "... the interview is not simply concerned with collecting data about life: it is part of life itself, its human embeddedness is inescapable." The researcher has to know and select the appropriate method for addressing the needs of the research question. Then, the researcher has to make a decision and choose the right method for that study. Data collection has its complexities and demands.

It is the role of the researcher to ask questions. The questions ought to elicit valid response from respondents. Hoyle, Harris and Judd (2002) comment that questions have "... dual goals of motivating the respondent to give full and precise replies while avoiding biases stemming from social desirability, conformity, or other constructs of disinterest." 


\subsection{FINDINGS}

The themes provide information on the benefits of using PBL from the perspectives of teachers. The theme consists of the following two subthemes: (1) Benefits of using PBL for teachers; (2) Benefits of using PBL for students.

\subsection{Benefits of using PBL for Teachers}

The identified benefits indicated in this study are: (1) Improved discipline and (2) Better teacher-students' relations.

\subsubsection{Improved Discipline}

Teachers reply that PBL is beneficial from them in terms of creating a pleasant atmosphere in the class and keeping discipline. For example, regarding this, the English language teachers says "It is students' task to do everything. In this case, it would be easier for the teacher to control them". This suggests that while the most part of the work is done by students, therefore, it is easier for teacher to organize students and keep discipline. The Physics teacher says: "During PBL students do not interrupt each other and it is easier for me to organize students for group work". In this case, we can see that teacher indicates the use of PBL in maintaining discipline in class and to manage his students to work in groups. According to the Mathematics teacher, when PBL is practised, there are a lot of opportunities for one to get to know the students. It is easier to find common points between the students. The teacher can easily control and motivate the students. This response also shows that the Mathematics teacher motivates his students, facilitates their learning and is able to organize them through getting to know them and finding common points. In conclusion, based on the teachers' responses, it is worthwhile to mention that PBL is helpful to create that pleasant collaborative atmosphere in the classroom in order to keep discipline and encourage students to take ownership of their own learning.

\subsubsection{Better teacher-student Relations}

One of the most important benefits of using PBL for teachers might the creation of good relationships with students. It might be vital due to the fact that deeper relations they have with their students and the more profoundly they know them, the more open students may be with them, and as a result, teachers might probably be more able to help them with their problems. According to the responses, all teachers in diverse ways indicate that PBL provides them with the opportunity to establish very good relationships with the students, which possibly leads to a more pleasant and collaborative atmosphere in the classroom. This in turn may encourage students to delve more profoundly into their project work and foster an atmosphere of collegiality and inquiry which supports the teaching and learning process. For example, the English language teacher mentioned that when the teacher gets closer to the students, he creates a warm relationship with them and there is more trust between the two. It is crucial to trust and have a trust with the students, as they will be more open and honest with the teacher. Based on the response, we can suggest that students do the given tasks with more pleasure, which makes it easier to work with them.

The Physics teacher suggests that teachers may have better relationships with their students when they focus on an individual approach. According to her, when a teacher works with the whole class, it is much more difficult to negotiate with every student and help them with their questions and problems. Moreover, the Mathematics teacher also positively responds to this problem" "I can really feel that we got closer to students. By solving social problems, we learned many new things about them". To sum up, all teachers agree that PBL helps them create better relationships with their students, learn a lot about them and help them with their questions and problems.

\subsection{Benefits of using PBL for Students}

Based on the teachers' responses the most important benefits of using PBL for students are the following ones: (1) Skill improvement, (2) Real-world practice, and (3) Better relationship among students. 


\subsubsection{Skill Improvement}

Most teachers believe that PBL helps students improve certain skills. For example, regarding this the Physics teacher says "Students develop their $21^{\text {st }}$ century skills, such as communication, creativity and critical thinking skills". They work in groups and have the opportunity to help each other because stronger students help weaker classmates understand particular topics on Physics". He claims that students working in groups could probably develop their communication skills, especially when they help each other. This suggests that while stronger students help the weaker ones they could also improve their mentoring skills. When students work in groups they may have different ideas and thoughts on particular topics. As a result, it could improve their creativity and critical thinking skills, as they will be free to discuss any upcoming ideas on the topic.

In the same way, the English Language teacher sheds more light on this perspective, "In this case, students will think not in the way you teach them, but they will get out of the box, they can have many great ideas". This suggests that students do not have to learn only what a teacher teaches; they have more space and freedom to be creative. Regarding skill improvement the Physics teacher says: "In my opinion, the most important benefit for students is that they can develop the hidden skill.....They also improve different skills, such as presentation and collaboration skills". He highlights the fact that the skills are hidden, which probably indicates that they may not develop these skills unless they engage in PBL. Moreover, the Physics teacher mentions presentation skills, which are improved when students present their project work. It can be seen from the responses that teachers believe that PBL helps students improve in several skill areas, become more creative and provide them with the opportunity to have new ideas and share them with the opportunity to have ideas and share them with each other.

\subsubsection{Real-world Practice}

One of the most important benefits of using PBL for students is the practice, as PBL provides them with the opportunity to go to the field and do the practical part of the project work. According to the Physics teacher: "In theory, it is not interesting for them, but when they do it by their hands it becomes more useful and engaging for them". According to the English Language teacher, students are not bounded merely by defined subjects, but they can observe anything they want, any area that might be interesting for them. It can be surveys, public opinions, and other real-world problems.

Concerning the real-world practice the Mathematics teacher says: "... solving real problems, make them feel so serious and confident". Students trying to deal with real existing issues will probably be very serious about them and understanding all upcoming consequences of their activities. As a result, it might raise the level of responsibility for their project work. In sum, it was described by the respondents that students are more engaged and involved in the learning process when they have enough real-world practice. Moreover, real-world issues are more interesting for students, as they may feel that they can be helpful in solving meaningful and existing problems, therefore take responsibility for their work.

\subsubsection{Better Relationship Between Students}

PBL provides teachers with opportunities to better know and have a good relationship with their students, which might be helpful for teachers in managing, organizing and guiding the class. Another benefit to mention is that PBL also helps students to be friendlier with each other and support their peers within each group. As PBL is a group work approach, students have a common task to finish and this possibly suggests that students within every group will try to equally contribute to the project and help their group mates when necessary.

The English Language teacher says on this issue: "working as a group they share ideas, listen to partners, trying to understand them, find the common points". Based on this statement, students in groups support group mates, listens to them and try to find common points. This suggests that by helping and sharing, students may have better relationships with each other. The Physics teacher mentions that students in groups support each other and explain difficult topics to those who do not understand sometimes even better than him. As a result, this indicates that while students help each other, they may have better relations with their peers. The Mathematics teacher regarding this issue claims: "It was really useful for me because strong students helped weak ones. Moreover, they have a better relationship with their friends during PBL". As in all responses, the 
Mathematics believes that PBL provides students with the opportunity to work in groups and support each other. This demonstrates that there is a strong relation between support and stronger relationships. PBL creates that positive and pleasant collaborative environment for learning which helps students to work more effectively and help each other grow within their groups.

To sum up, there are many benefits for students using PBL and the most important one are as follows: the improvement of certain skills, opportunity to deal with real practical work and better relationship with peers. However, there are also some extra advantages of using PBL for students. For example, the Mathematics teacher says: "shy students can show their abilities". This could suggest that PBL welcomes diversity and helps various students express themselves in a different manner. One of the most crucial benefits for students might be the use of gained skills and abilities at University. Regarding this the English Language teacher says: "I think when they go to university it will be easier for them to make different projects because they have learned all the necessary strategies". According to all the quotes, PBL is beneficial for the students in many aspects.

\subsection{CONCLUSION}

There is a need to understand that no two teachers perceive PBL in the same way, as every teacher is unique and has different background and experience. The findings of this study suggests that there are wide-ranging perceptions of $\mathrm{PBL}$, however, some of them were identified as the most common and frequently mentioned ones. Teachers perceived PBL in three major aspects. The first one is self-learning, which means that PBL is a more student-centered approach. Findings also suggests that teachers are only facilitators who direct students. The second aspect is increased engagement, which means that PBL raises students' interest in learning because during PBL students are provided with opportunities to deeply investigate topics that are meaningful and interesting to them. Lastly, teachers perceive PBL through better understanding of the subject. In this regard, PBL provides students with opportunities of collaboration, practicing theoretical knowledge and engaging in real existing problems, which contribute to their better understanding of subject content.

Considering all the benefits found in this study and the influence of PBL on students' success in project completions, policymakers could think about incorporating PBL into every subject as a mandatory part of the final grade in Malaysian schools. One part of the lesson could remain theoretical in a teacher-centered manner; however, the second part could be more practical in a student-centered style. As a result, this could help teachers and students shift from teacher-oriented approach to student-centered learning more gradually. Furthermore, PBL being implemented as a mandatory part of the subject would probably require teachers and students to spend less of their own time after lesson, as it would be partially done during the lesson. This could possibly contribute to the solution of the identified challenge concerning lack of time.

\section{REFERENCES}

1. Baş, G. (2011). Investigating the effects of project-based learning on students' academic achievement and attitudes towards English lesson. The online journal of New Horizons in Education, 1(4), 1-15.

2. Baumgartner, E., \& Zabin, C. J. (2008). A case study of project-based instruction in the ninth grade: A semester-long study of intertidal biodiversity. Environmental Education Research, 14(2), 97-114.

3. Baysura, O. D., Altun, S., \& TOY, B. Y. (2016). Perceptions of teacher candidates regarding project-based learning. Eurasian Journal of Educational Research, 16(62).

4. Bell, S. (2010). Project-based learning for the 21st century: Skills for the future. The Clearing House, 83(2), 39-43.

5. Blumenfeld, P. C., Soloway, E., Marx, R. W., Krajcik, J. S., Guzdial, M., \& Palincsar, A. (1991). Motivating project-based learning: Sustaining the doing, supporting the learning. Educational psychologist, 26(3-4), 369-398.

6. Cohen, L., Manion, L., \& Morrison, K. (2000). Action research. Research methods in education, 5, 226-244. 
7. Creswell, J.W. (2009). Research Design: Qualitative, Quantitative, and Mixed Methods Approaches. Thousand Oaks, Ca: SAGE Publications.

8. Creswell, J.W. (2012). Educational Research. Planning, Conducting, and Evaluation Quantitative and Qualitative Research. Boston, MA: Pearson Education.

9. DiEnno, C. M., \& Hilton, S. C. (2005). High school students' knowledge, attitudes, and levels of enjoyment of an environmental education unit on nonnative plants. The journal of environmental education, 37(1), 13-25.

10. Fallik, O., Eylon, B., \& Rosenfeld, S. (2003). Novice and expert teachers' perceived benefits and difficulties of project-based learning (PBL). In Conference Proceeding for the 10th European Association Conference for Research on Learning and Instruction (EARLI), Padova, Italy.

11. Harrigan, G. (2014). A case study of teachers' and administrators' experiences integrating project-based learning. (Unpublished doctoral dissertation) Walden University, Minneapolis, MN.

12. Hugerat, M. (2016). How teaching science using project-based learning strategies affects the classroom learning environment. Learning Environments Research, 19(3), 383-395.

13. Hancock, D.R. \& Alogzzine, B. (2011). Doing Case Study Research: A Practical Guide for Beginning Researchers. New York, NY: Teachers College Press.

14. Harmer, N., \& Stokes, A. (2014). The benefits and challenges of project-based learning. A review of the literature, Internet. United Kingdom: Plymouth University, 38.

15. Holm, M. (2011). Project-based Instruction: A Review of the Literature on Effectiveness in Prekindergarten. River academic journal, 7(2), 1-13.

16. Hoyle, R. H., Harris, M. J., \& Judd, C. M. (2002). Research methods in social relations. Thomson Learning.

17. Jones, B. F., Rasmussen, C. M., \& Moffitt, M. C. (1997). Real-life problem solving: A collaborative approach to interdisciplinary learning. American Psychological Association.

18. Kahn, P., \& O’Rourke, K. (2004). Guide to curriculum design: Enquiry-based learning. Higher Education Academy, 30(3).

19. Kolmos, A. (2009). Problem-based and project-based learning. In University science and mathematics education in transition (pp. 261-280). Springer, Boston, MA.

20. Krajcik, J. S., \& Blumenfeld, P. C. (2006). Project-based learning. In The Canbridge Handbook of the Learning Sciences (pp. 317-34). R.Keith Sawyer (ed). Cambridge: Cambridge University Press.

21. Kubiatko, M., \& Vaculová, I. (2011). Project-based learning: characteristic and the experiences with application in the science subjects. Energy Education Science and Technology Part B: Social and Educational Studies, 3(1), 65-74.

22. Kvale, S. (1996). The 1,000-page question. Qualitative inquiry, 2(3), 275-284.

23. Larmer, J., Mergendoller, J., \& Boss, S. (2015). Setting the standard for project based learning. ASCD. Retrieved

from http://www.ascd.org/ASCD/pdf/siteASCD/publications/books/Setting-the-Standard-for-PBL-sample-c hapters.pdf

24. Lehmann, M., Christensen, P., Du, X., \& Thrane, M. (2008). Problem-oriented and project-based learning $(\mathrm{POPBL})$ as an innovative learning strategy for sustainable development in engineering education. European journal of engineering education, 33(3), 283-295.

25. Lodico, M. G., Spaulding, D. T., \& Voegtle, K. H. (2010). Methods in educational research: From theory to practice (Vol. 28). John Wiley \& Sons. 
26. Merriam, S. B. (2009). Qualitative Research: a guide to design and interpretation. San Francisco: Jossey-Bass.

27. Nicola, H., \& Allison, S. (2014). The benefits and challenges of project Based Learning. Pedagogic Research Institute and Observatory (PedRIO). Plymouth University.

28. Perrenet, J., \& Adan, I. (2002). From mathematical modelling to design based learning; a bridge too far?. International Journal of Mathematical Education in Science and Technology, 33(2), 187-197.

29. Ravitz, J., \& Blazevski, J. (2010, October). Assessing the impact of online technologies on PBL use in US high schools. In Annual Meetings of the Association for Educational Communications and Technology. Anaheim, CA.

30. Tamim, S. R., \& Grant, M. M. (2013). Definitions and uses: Case study of teachers implementing project-based learning. Interdisciplinary Journal of Problem-Based Learning, 7(2), 3.

31. Thomas, J. W. (2000). A review of research on project-based learning. Retrieved from http://www.bie.org/images/uploads/general/9d06758fd346969cb63653d00dca55c0pdf

32. Van den Bergh, V., Mortelmans, D., Spooren, P., Van Petegem, P., Gijbels, D., \& Vanthournout, G. (2006). New assessment modes within project-based education-the stakeholders. Studies in educational evaluation, 32(4), 345-368.

33. Von Kotze, A., \& Cooper, L. (2000). Exploring the transformative potential of project-based learning in university adult education. Studies in the Education of Adults, 32(2), 212-228.

34. Worthy, J. (2000). Conducting research on topics of student interest. Reading Teacher, 54(3), 298-299.

35. Yam, L. H., \& Rossini, P. A. (2010). Implementing a project-based learning approach in an introductory property course. (Doctoral dissertation, PRRES). Wellington, New Zealand.

36. Yazzie-Mintz, E. (2010). Leading for Engagement. Principal Leadership, 10(7), 54-58. 